\title{
Maximising co-creation strategy through integration of distinctive capabilities and customer experiences in supply chain management
}

\author{
Leonardus W. Wasono Mihardjo ${ }^{a^{*}}$, Sasmoko ${ }^{a}$, Firdaus Alamsyaha and Elidjen ${ }^{a}$
}

${ }^{a}$ Bina Nusantara University, West Jakarta, Indonesia

\begin{tabular}{l}
\hline C H R O N I C L E \\
\hline Article history: \\
Received June 7, 2019 \\
Received in revised format June \\
25,2019 \\
Accepted July 122019 \\
Available online \\
July 142019 \\
\hline Keywords: \\
Co-creation strategy \\
Distinctive capabilities \\
Customer experience \\
Supply chain
\end{tabular}

\section{Introduction}

Industry 4.0 drives businesses into more complex and dynamic. By increasing the complexity, not all value chains can be fulfilled by internal capabilities, therefore the collaboration with stakeholders to accelerate processes and innovate business models is important and provide co-creation value to stakeholders (Zott et al., 2011). There are several studies which indicate the significant impact on the acceleration of value creation in an established company, especially on consumer sectors (Fuller, 2010). To anticipate the complexity of products and services, several solutions can be delivered (Kagermann, 2015) such as sharing economy (Matzner et al., 2018), virtualization (Monios \& Bergqvist, 2015), and transforming traditional businesses to be more innovative, standardized, modular, interoperable, decentralized, real-time, virtualized and service-oriented (Ibarra et al., 2019). The co-creation concept was first adopted in the marketing context to develop innovation and value creation capabilities by providing value and collaboration with customers and minimize the cost of exploring innovation (Prandelli et al., 2006; Sawhney et al., 2005; Stamm, 2004). Co-creation will drive the personalization of services and products for customers, while optimizing digital technology such as big data, CRM, and digital marketing will leverage customer value, with an expectation that customers gain experience (Prahalad \& Ramaswamy, 2000)

* Corresponding author

E-mail address: mihardjo@gmail.com (L.W.W. Mihardjo)

(C) 2020 by the authors; licensee Growing Science. doi: $10.5267 /$ j.uscm.2019.7.005

\author{
(1)
}


Developing of co-creation with customer and other parties could be accelerated when customer has experience to sustain the business (Gentile et al., 2007; Ramaswamy, 2011; Romero \& Molina, 2009) through better customer relation (Bolton, 2016; Lemke et al., 2011), better product and service quality (Lemke et al., 2011), higher customer loyalty (Brakus et al., 2009; Fatma, 2014), and also reducing the risks to company (Romero \& Molina, 2009) since the core of customer experience is associated with the personal of customers (Ramaswamy, 2011). Looking at the benefits of co-creation and customer experience in digital context, the need to extend the scope of co-creation is not only for customers but also for stakeholders and to place it at a strategy level to gain more attention. This will have impact on improving organization capability and need to distinct the capability compared with the competitors ( Prahalad \& Ramaswamy, 2004).

The distinct capability is required to ensure the company focus on strong capability in developing core competence (Prahalad \& Hamel, 1990). In Supply chain management the distinct capabilities have become the key capabilities development where capabilities shall rely on input of customer experience and enable co-creation with customer and partners (MYNBAYEBA et al. 2018). The study on developing network-centric in developing co-creation as part of integration by combination of customer experience and distinctive capability is still limited with few studies (Coombes \& Nicholson, 2013). The current literature views on co-creation focus on collaboration, while on customer experience and capability with customers in terms of constructs, applicability and benefit, hence, we present the concept model of digital transformation based on co-creation strategy to evaluate the role of co-creation and its relationship with customer experience and distinctive capability. The paper starts with introduction, literature review, and methodology based on empirical study on Indonesia telecommunication study, and discussion, conclusion with limitation and future development will presented next.

\section{Literature Review}

\subsection{Customer Experience}

The concept of customer experience has been discussed for more than 15 years but still some clarifications are needed (Sheth \& Uslay, 2007). There is still some confusion between customer experience and Customer Relation Management (CRM). CEM is more than having a relationship with customers, but involves a multidimensional view, including the process, brand, and perception. This also includes sensory (sense), affective (feeling), cognitive (thinking), physical (act), and socialidentity (relation) experiences (Bolton, 2016). Personalisation is a key success, especially when the digital technology is applied where trust is the main driver (Henfridsson et al., 2014).

CEM as a process that involves the entire experience of customers having an interaction with lifecycle customers. CEM as a brand is part of perception based on customer experience associated with previously purchased brands across the touch screen and amplification of the brand's intentions. CRM is a part of how customers can experience. Customer experience is constructed in a holistic manner related to the customer's cognitive, affective, emotional, social, and physical responses. in retailing context, customer experiences can be categorized along the lines of the retail mix (i.e., price experience, promotion experience) (Grewal et al., 2009). Based on the literature review, customer experience in this study is measured by dimensions including price and promotion, CRM \& data analytics, trust \& personalization, and brand performance (Lambekova et al., 2017).

\subsection{Distinctive Capability}

The concept of capability is defined as an organizational process, system or routine used by an organization to coordinate resources for productive use (Hubbard \& Beamish, 2011). The distinctive capability concept is derived from the core competence concept to sustain the business (Coimbatore et 
al., 1990) The distinctive capability is embedded in an organization as a collection of unique resources and capabilities. The competitive advantage of organizations depends on resources, capabilities, and core competency resources defined as a source to create organizational capabilities. Whereas, capability is the source of core competencies (Hitt et al., 2015). In a digital transformation, the distinctive capability starts from leadership, people and culture (Jacobi \& Brenner, 2017).

The digital leadership is the enable for transformation defined as a digital visioning to optimize the use of digital technology as part of combination of digital competence and culture (Rudito et al., 2017; Wasono \& Furinto, 2018). In terms of process, digital technology has the ability to shorten the distribution process through the digitization process and improve the personalized service (Parise et al., 2016). The digital technology change drives the firm capability to adopt and agility towards market dynamics and the governance as important factors (Kohli \& Johnson, 2011). In this study, distinctive capability uses digital leadership value, digital culture and competence, digitation \& agile operation, and governance as its dimensions.

\subsection{Co-creation strategy}

The concept of co-creation is derived from marketing literature, where the marketing transaction is transformed into collaboration with customers as the main focus of companies (Prahalad \& Ramaswamy, 2000; Ramaswamy \& Ozcan, 2013; David Romero \& Molina, 2011). The co-creation concept involves customer as part of the value chain business and as part of open innovation interconnect with other people (Ramírez-Montoya \& García-Peñalvo, 2018). The collaboration is ranging from co-design, co-production, co-delivery to co-promotion as part of the real time learning (Frow et al., 2015; Gerlitz, 2015).

Hence, in the development of co-creation, it will be a more holistic to use the value chain approach and integrates it with existing assets and processes to achieve the performance according to revenue, cost and quality (Hamidi \& Shams Gharneh, 2017; Roser et al., 2013). In this study, co-creation strategy is assessed by the dimensions of real-time learning, interoperability \& integration, interconnection \& collaboration, quality, and revenue \& cost (Kozhukhova et al. 2019). The customer experience has positive relationship with developing co-creation (Ramaswamy, 2011; Ramaswamy \& Ozcan, 2013; D Romero \& Molina, 2009). Co-creation can be developed as part of the process of value creation in developing customer experience, hence we formulate the first hypothesis as follow:

Hypothesis 1: Customer experience has significant influence on co-creation strategy in the Indonesian ICT industry.

Distinctive organization capability as internal factor of the firm has positive influence to co-creation (Leonardus Wahyu Wasono Mihardjo et al., 2018) as part of organization capabilities (Sharma et al., 2014), digitation process (Lenka et al., 2017) and leadership (Leonardus et al., 2018).

Hypothesis 2: Distinctive capability has significant influence on co-creation strategy in the Indonesian ICT industry.

The research model is shown in Fig. 1.

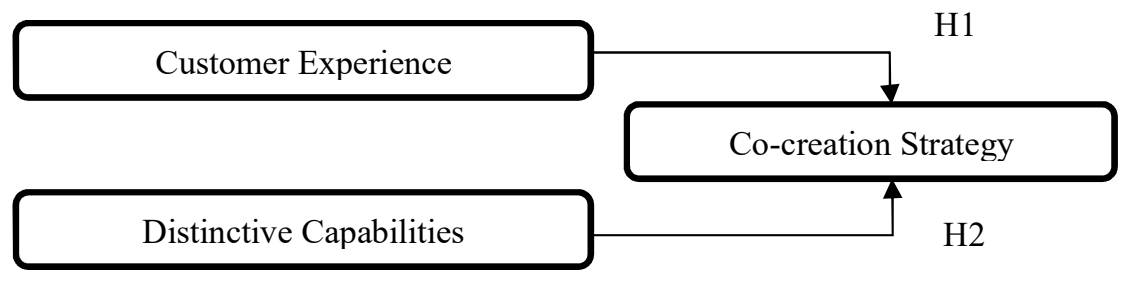

Fig. 1. The Research Model Framework 


\section{Methodology}

This study was conducted through empirical research using a sample of 35 Indonesian ICT firms as a prototype of the research model in co-creation strategy. Purposive sampling is used, analytical tool and solution technique are also implemented based on smart PLS. Respondents participated in this research are people holding managerial positions in the ICT industry, with the respondent distribution as follows :

\section{Table 1}

Sample Respondents

\begin{tabular}{lcccc}
\hline \multicolumn{1}{c}{ Segment } & Board/C Level & VP Levels & GM Level & Mgr Level \\
\hline Network Provider & 3 & 16 & 3 & 1 \\
Service Provider & 2 & 1 & 3 & 0 \\
Partners & 4 & 0 & 1 & 1 \\
\hline TOTAL & $\mathbf{9}$ & $\mathbf{1 7}$ & $\mathbf{7}$ & $\mathbf{2}$ \\
\hline
\end{tabular}

$65 \%$ respondents are in network provider, while $17 \%$ in service provider and the rest $17 \%$ are partners who support network and service providers in the supply chain and collaboration.

\section{Results}

PLS consists of inner and outer models. The analysis of inner model shows the relationship between latent variables - dimensions and indicators. Inner model is evaluated by using goodness-of-fit Model (GoF) which shows the difference between the values of the observation results with values predicted by the model.

\section{Table 2}

Goodness of fit Model

\begin{tabular}{|c|c|c|c|c|}
\hline Variable & $\begin{array}{l}\text { Cronbach's } \\
\text { Alpha }\end{array}$ & $\begin{array}{l}\text { Composite } \\
\text { Reliability }\end{array}$ & R Square & Q square \\
\hline CUSTOMER EXP & 0.918 & 0.929 & - & 0.413 \\
\hline DISTINCTIVE CAPABILITY & 0.910 & 0.926 & - & 0.532 \\
\hline CO -CREATION STRATEGY & 0.940 & 0.950 & 0.651 & 0.662 \\
\hline
\end{tabular}

Table 2 shows the value of $\mathrm{R}^{2}$ of co-creation strategy as an endogenous variable is in the strong criteria and the value of Q square is in the large criteria. So, it can be concluded that the research model is either supported by empirical conditions, or the model is fit.

\subsubsection{Measurement Model (outer model)}

Analysis of the outer model is used as a validity and reliability test to measure latent variables and indicators in measuring dimension that is constructed. Composite reliability and Cronbach's Alpha of variables $>0,70$ show that all of variables in the estimated model fulfil the criteria of discriminant validity. It can be concluded that all of the variables have a good reliability.

Table 3

Loading Factor of Latent Variable-Dimension-Indicator

\begin{tabular}{|c|c|c|c|}
\hline Indicator-Dimension & $\lambda$ & $\operatorname{SE}(\lambda)$ & t-value \\
\hline CUSTOMER EXP $\rightarrow$ Price and Promotion & 0.561 & 0.073 & $7.705^{*}$ \\
\hline PP1 $\leftarrow$ Price and Promotion & 0.792 & 0.069 & $11.555^{*}$ \\
\hline PP $2 \leftarrow$ Price and Promotion & 0.729 & 0.078 & $9.400 *$ \\
\hline PP3 $\leftarrow$ Price and Promotion & 0.860 & 0.030 & $28.226^{*}$ \\
\hline CUSTOMER EXP $\rightarrow$ CRM \& Data Analytics & 0.864 & 0.014 & $63.350^{*}$ \\
\hline CRM1 $\leftarrow$ CRM \& Data Analytics & 0.826 & 0.043 & $19.144 *$ \\
\hline CRM $2 \leftarrow$ CRM \& Data Analytics & 0.905 & 0.019 & $48.036^{*}$ \\
\hline CRM $3 \leftarrow$ CRM \& Data Analytics & 0.800 & 0.035 & $22.672 *$ \\
\hline
\end{tabular}


Table 3

Loading Factor of Latent Variable-Dimension-Indicator (Continued)

\begin{tabular}{|c|c|c|c|}
\hline CUSTOMER EXP $\rightarrow$ Trust \& personalization & 0.874 & 0.025 & $34.708^{*}$ \\
\hline TP1 $\leftarrow$ Trust $\&$ personalization & 0.773 & 0.054 & $14.379 *$ \\
\hline TP2 $\leftarrow$ Trust $\&$ personalization & 0.881 & 0.027 & $32.272 *$ \\
\hline TP $3 \leftarrow$ Trust $\&$ personalization & 0.760 & 0.037 & $20.557 *$ \\
\hline TP4 $\leftarrow$ Trust $\&$ personalization & 0.783 & 0.060 & $13.056^{*}$ \\
\hline CUSTOMER EXP $\rightarrow$ Brand Performance & 0.878 & 0.041 & $21.173 *$ \\
\hline $\mathrm{BP} 1 \leftarrow$ Brand Performance & 0.610 & 0.072 & $8.513 *$ \\
\hline $\mathrm{BP} 2 \leftarrow$ Brand Performance & 0.805 & 0.052 & $15.587 *$ \\
\hline $\mathrm{BP} 3 \leftarrow$ Brand Performance & 0.803 & 0.075 & $10.673 *$ \\
\hline BP4 $\leftarrow$ Brand Performance & 0.928 & 0.017 & $53.886^{*}$ \\
\hline BP5 $\leftarrow$ Brand Performance & 0.675 & 0.082 & $8.210^{*}$ \\
\hline BP6 $\leftarrow$ Brand Performance & 0.598 & 0.080 & $7.440 *$ \\
\hline BP7 $\longleftarrow$ Brand Performance & 0.803 & 0.052 & $15.456^{*}$ \\
\hline BP8 $\leftarrow$ Brand Performance & 0.863 & 0.036 & $23.841 *$ \\
\hline DISTINCTIVE CAPABILITY $\rightarrow$ Digital leadership value & 0.882 & 0.021 & $42.975^{*}$ \\
\hline DV1 $\leftarrow$ Digital leadership value & 0.680 & 0.073 & $9.335^{*}$ \\
\hline DV2 $\leftarrow$ Digital leadership value & 0.918 & 0.018 & $51.762 *$ \\
\hline DV3 $\leftarrow$ Digital leadership value & 0.730 & 0.077 & $9.526^{*}$ \\
\hline DISTINCTIVE CAPABILITY $\rightarrow$ Digital culture and competence & 0.923 & 0.019 & $47.732 *$ \\
\hline $\mathrm{DC} 1 \leftarrow$ Digital culture and competence & 0.883 & 0.020 & $44.102 *$ \\
\hline $\mathrm{DC} 2 \leftarrow$ Digital culture and competence & 0.890 & 0.024 & $36.843^{*}$ \\
\hline DC3 $\leftarrow$ Digital culture and competence & 0.761 & 0.053 & $14.422 *$ \\
\hline DISTINCTIVE CAPABILITY $\rightarrow$ Digitation $\&$ agile operation & 0.949 & 0.010 & $92.843^{*}$ \\
\hline DA $1 \leftarrow$ Digitation $\&$ agile operation & 0.843 & 0.050 & $16.836^{*}$ \\
\hline DA2 $\leftarrow$ Digitation $\&$ agile operation & 0.815 & 0.048 & $17.018^{*}$ \\
\hline DA3 $\leftarrow$ Digitation $\&$ agile operation & 0.857 & 0.031 & $28.039 *$ \\
\hline DISTINCTIVE CAPABILITY $\rightarrow$ Governance & 0.662 & 0.045 & $14.568^{*}$ \\
\hline GOV $\leftarrow$ Governance & 1.000 & 1.00 & 100 -* \\
\hline CO -CREATION STRATEGY $\rightarrow$ Real Time Learning & 0.859 & 0.041 & $20.769^{*}$ \\
\hline RTL1 $\leftarrow$ Real Time Learning & 1.000 & 1000 & $1000-*$ \\
\hline CO -CREATION STRATEGY $\rightarrow$ Interoperability $\&$ Integration & 0.941 & 0.020 & $47.201 *$ \\
\hline III $1 \leftarrow$ Interoperability \& Integration & 0.937 & 0.019 & $50.597 *$ \\
\hline II $2 \leftarrow$ Interoperability \& Integration & 0.941 & 0.016 & $58.800 *$ \\
\hline CO -CREATION STRATEGY $\rightarrow$ Interconnect $\&$ Collaboration & 0.952 & 0.012 & $76.989 *$ \\
\hline $\mathrm{IC} 1 \leftarrow$ Interconnect $\&$ Collaboration & 0.851 & 0.040 & $21.435^{*}$ \\
\hline IC2 $\leftarrow$ Interconnect $\&$ Collaboration & 0.839 & 0.047 & $17.823 *$ \\
\hline IC3 $\leftarrow$ Interconnect $\&$ Collaboration & 0.760 & 0.103 & 7.404* \\
\hline IC4 $\leftarrow$ Interconnect $\&$ Collaboration & 0.718 & 0.084 & $8.589^{*}$ \\
\hline CO-CREATION STRATEGY $\rightarrow$ Quality, Revenue $\&$ Cost & 0.962 & 0.013 & $74.857 *$ \\
\hline QRC1 $\leftarrow$ Quality, Revenue \& Cost & 0.816 & 0.033 & $24.463 *$ \\
\hline QRC2 $\leftarrow$ Quality, Revenue \& Cost & 0.909 & 0.015 & $59.052 *$ \\
\hline QRC3 $\leftarrow$ Quality, Revenue \& Cost & 0.803 & 0.068 & $11.735^{*}$ \\
\hline
\end{tabular}

\subsubsection{Structural Model and Hypothesis Testing}

The figure shows the complete path diagram based on structural model testing:

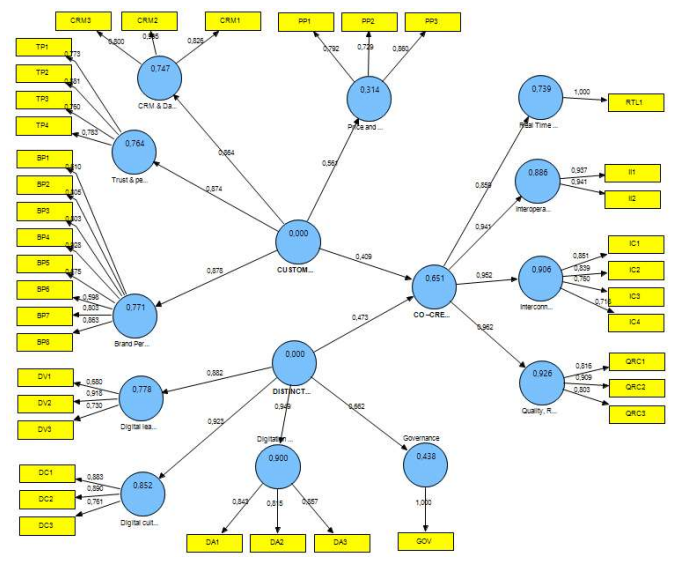

Fig. 2. Structural Model Result 


\subsection{Hypothesis testing}

\section{a. Simultaneous Hypothesis testing}

Below is the result of simultaneous testing of the hypothesis:

Table 4

Simultaneous Testing of Hypothesis

\begin{tabular}{llrrc}
\hline \multicolumn{1}{c}{ Hypothesis } & $\mathbf{R}^{\mathbf{2}}$ & $\mathbf{F}$ & \multicolumn{1}{c}{ Conclusion } \\
\hline Customer & Experience and Distinctive & 0.651 & $29.876^{*}$ & Hypothesis accepted \\
Capability $\rightarrow$ Co - Creation Strategy & & & & \\
* significant at $\alpha=0.05$ & (F table $=3.295)$
\end{tabular}

Table 4 shows that within the degree of confidence of $95 \%(\alpha=0.05)$, simultaneously customer experience and distinctive capability influence co-creation strategy, amounted to $65.1 \%$, while the $34.9 \%$ is affected by other factors that were not examined.

\section{b. Partial Hypothesis testing}

Below is the result of partial testing of the hypothesis :

Table 5

Partial Testing of Hypothesis

\begin{tabular}{lccccc}
\hline \multicolumn{1}{c}{ Hypothesis } & $\gamma$ & SE $(\gamma)$ & t & R2 & Conclusion \\
\hline $\begin{array}{l}\text { CUSTOMER EXP } \rightarrow \text { CO - } \\
\text { CREATION STRATEGY }\end{array}$ & 0.409 & 0.110 & $3.727^{*}$ & 0.297 & $\begin{array}{c}\text { Hypothesis } \\
\text { accepted }\end{array}$ \\
$\begin{array}{l}\text { DISTINCTIVE CAPABILITY } \rightarrow \text { CO } \\
\text {-CREATION STRATEGY }\end{array}$ & 0.473 & 0.103 & $4.594^{*}$ & 0.354 & $\begin{array}{c}\text { Hypothesis } \\
\text { accepted }\end{array}$ \\
\hline
\end{tabular}

* significant at $\alpha=0.05$ (t table $=2.03)$

Table 5 shows that partially, customer Experience and distinctive capability significantly influence cocreation strategy, in which distinctive capability has greater influence (35.4\%). Based on the hypothesis testing, the findings can be represented by the figure below:

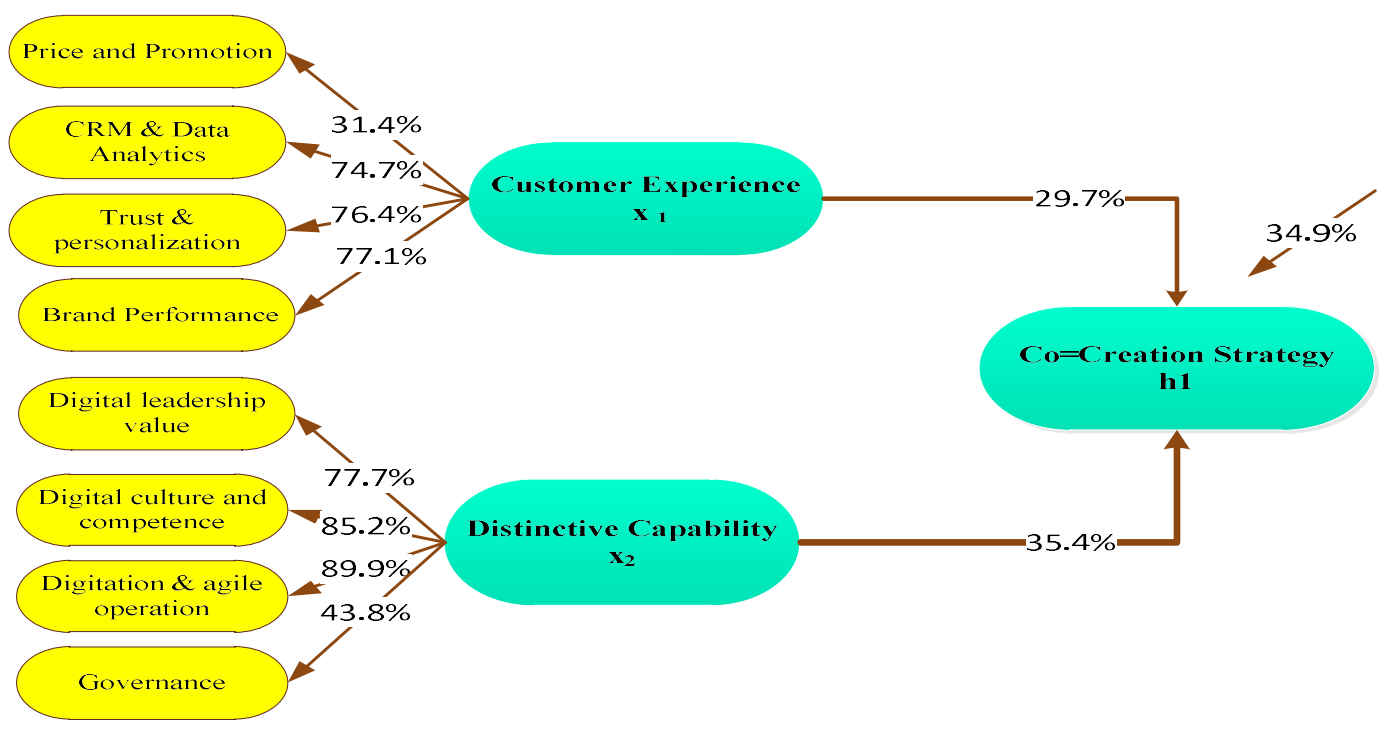

Fig. 3. Research Findings 


\section{Discussion and Implication}

The findings of this study indicate that there was a significant, positive effect of customer experience and distinctive capability on co-creation strategy, indicating that the hypothesis is accepted. Distinctive capability has a greater influence (35.4\%) than customer experience $(29.7 \%)$ in improving co-creation strategy. Based on these findings, it can be said that the development of co-creation strategy in the ICT industry requires the implementation of distinctive capability and customer experience in an integrated way to deal with Industry 4.0. The development of distinctive capability in the ICT industry should be based on the development of digitation and agile operation, followed by the development of digital culture and competence, digital leadership value, and governance. On of practical implementation is in supply chain management. In supply chain management, the capability to develop collaboration through optimize the use of digital technology, such as cloud, big data and mobile become key factors in developing co-creation. The supply chain capability is required to develop and to enable the collaboration and co-creation with partner and customers. In addition, co-creation strategy also needs to be executed through the development of customer experience, especially by improving brand performance. Trust and personalization, CRM and data analytics, review, price and promotion also need to be improved.

This is having implication for practitioner in developing transformation supply chain management for supporting business, the framework for transformation based on the three pillars: co-creation strategy, customer experience and distinctive capability with the model as created based on the following Framework:

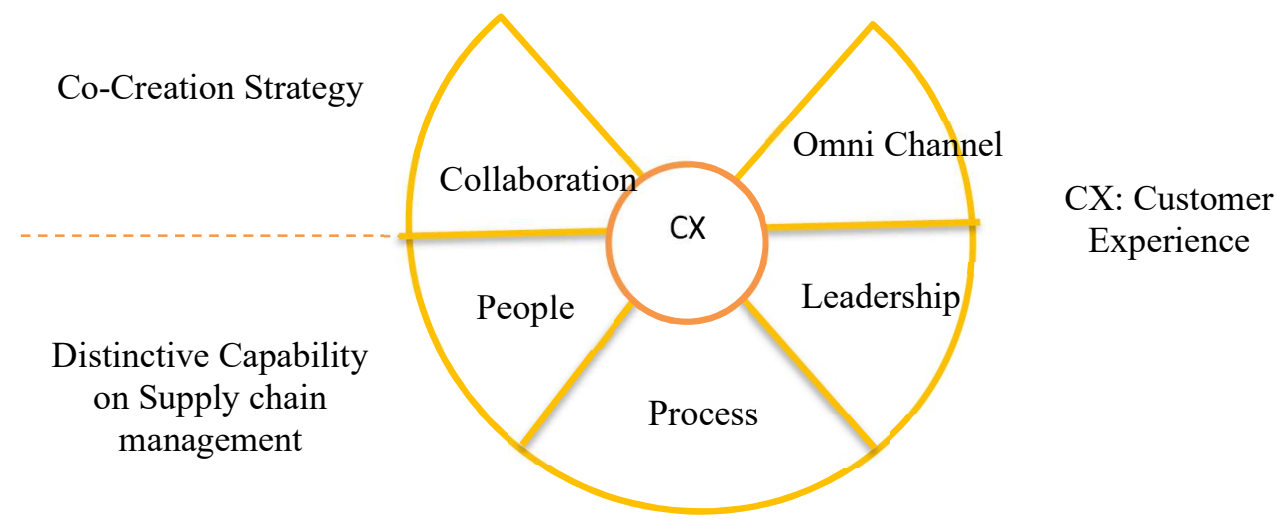

Fig. 4. Transformation Model

(Seppanen \& Laukkanen, 2016)

This has implication that co-creation is part of customer and partner journey has strong relationship through omnichannel (digital and physical channel) with customer experience and distinctive capabilities where customer experience is the centre on development co-creation and distinctive capabilities. Distinctive capability in supply chain management could be created through people, digitation process and enable vision and leadership to determine supply chain capability.

\section{Conclusion and Recommendation}

The findings of this study support the hypothesis that customer experience and distinctive capability have significant, positive effects on co-creation strategy. Distinctive capability has a greater impact than customer experience in improving co-creation strategy. The study has practical implications as a reference model that illustrates how the firms create co-creation strategy in interconnected activities. Further studies can be conducted by extending the sample to ICT Industries in countries other than 
Indonesia for analysis.. Further studies can also be conducted in other countries with similar market characteristics to support the current findings. Since the transformation takes a longer amount of time, longitudinal exploration is required to ensure the research model is aligned with market dynamics.

\section{References}

Bolton, R. N. (2016). Service excellence: Creating customer experiences that build relationships. (N. Maholtra, Ed.). New York: Business Expert Press, LLC. Retrieved from http://www.ruthnbolton.com/Webinar160915_Bolton.pdf

Brakus, J. J., Schmitt, B. H., \& Zarantonello, L. (2009). Brand experience: What is it? How is it measured? Does it affect loyalty? Journal of Marketing, 73(3), 52-68.

Coombes, P. H., \& Nicholson, J. D. (2013). Business models and their relationship with marketing: A systematic literature review. Industrial Marketing Management, 42(5), 656-664.

Fatma, S. (2014). Antecedents and consequences of customer experience management- A literature review and research agenda. International Journal of Business and Commerce, 3(6), 32-49.

Frow, P., Nenonen, S., Payne, A., \& Storbacka, K. (2015). Managing co-creation design: A strategic approach to innovation. British Journal of Management, 26(3), 463-483.

Fuller, J. (2010). Refining virtual co-creation from a consumer perspective. California Management Review, 52(2), 98-122.

Gentile, C., Spiller, N., \& Noci, G. (2007). How to sustain the customer experience: An overview of experience components that co-create value with the customer. European Management Journal, $25(5), 395-410$.

Gerlitz, L. (2015). Design for product and service innovation in industry 4.0 and emerging smart society. Journal of Security and Sustainability Issues, 5(2), 489-499.

Grewal, D., Levy, M., \& Kumar, V. (2009). Customer experience management retailing an organizing framework. Journal of Retailing, 85(1), 1-14.

Hamidi, F., \& Shams Gharneh, N. (2017). Impact of co-creation on innovation capability and firm performance: a structural equation modeling. AD-Minister, (june), 73-90.

Henfridsson, O., Mathiassen, L., \& Svahn, F. (2014). Managing technological change in the digital age: The role of architectural frames. Journal of Information Technology, 29(1), 27-43.

Hitt, M., Ireland, \& Hoskisson. (2015). Strategic Management Competitiveness \& Globalization Concepts and Cases (12 ${ }^{\text {th }}$ ed.). Sout-Western College Pub.

Hubbard, G., \& Beamish. P. (2011). Strategic Management: Thinking, Analysis and Action (4 ${ }^{\text {th }}$ ed.). Sydney Australia: Pearson.

Ibarra, D., Ganzarain, J., \& Igartua, J. I. (2018). Business model innovation through Industry 4.0: A review. Procedia Manufacturing, 22, 4-10.

Jacobi, R., \& Brenner, E. (2017). How large corporations survive digitalization. In Digital Marketplaces Unleashed (pp. 83-97).

Kagermann, H. (2015). Change through digitization-value creation in the age of industry 4.0. In Management of Permanent Change (pp. 23-32).

Kohli, R., \& Johnson, S. (2011). Digital Transformation in Latecomer Industries: CIO and CEO Leadership Lessons from Encana Oil \& Gas (USA) Inc. MIS Quarterly Executive, 10(4), 141-156.

Kozhukhova, M., Amanzholova, B., \& Zhiyenbayev, M. (2019). The Legal Regulation of Energy Efficiency and Energy Saving Policies in the Republic of Kazakhstan. International Journal of Energy Economics and Policy, 9(4), 54-62.

Lambekova, A., Nurgalieva, A., Syzdykova, E., Zhanibekova, G., \& Aff, J. (2017). Development of internal audit. Journal of Advanced Research in Law and Economics, 8(30), 2483-2489.

Lemke, F., Clark, M., \& Wilson, H. (2011). Customer experience quality: An exploration in business and consumer contexts using repertory grid technique. Journal of the Academy of Marketing Science, 39(6), 846-869.

Lenka, S., Parida, V., \& Wincent, J. (2017). Digitalization capabilities as enablers of value co-creation in servitizing firms. Psychology \& Marketing, 34(1), 92-100. 
Matzner, M., Büttgen, M., Demirkan, H., Spohrer, J., Alter, S., Fritzsche, A., ... Neely, A. (2018). Digital transformation in service management. Journal of Service Management Research, 2(May), $2-21$.

Mihardjo, L. W. W., Sasmoko, Alamsjah, F., \& Elidjen. (2018). The Role of Distinctive Organization Capability and Corporate Reputation in Formulating Co-Creation Strategy in the Age of Industry 4 . 0: Study on Indonesian Telecommunication Firms. The Journal of Social Sciences Research, 2(Special issue), 842-850.

Mihardjo, L. W. W., Sasmoko, S., Alamsjah, F., \& Elidjen, E. (2018). the Role of Distinctive Organisational Capability in Formulating Co-Creation Strategy and Business Model Innovation. Polish Journal of Management Studies, 18(2), 197-208.

Monios, J., \& Bergqvist, R. (2015). Using a "virtual joint venture" to facilitate the adoption of intermodal transport. Supply Chain Management, 20(5), 534-548.

MYNBAYEBA, D., NURGALIYEVA, A., ALISHEVA, D., DUISENBAYEVA, B., \& KULUMBETOVA, D. (2018). Application of the Holt-Winters Model for Predicting the Cost and Profitability of Bank Bonds. Journal of Applied Economic Sciences, 13(8).

Parise, S., Guinan, P. J., \& Kafka, R. (2016). Solving the crisis of immediacy: How digital technology can transform the customer experience. Business Horizons, 59(4), 411-420.

Prahalad, C. K., \& Hamel, G. (1990). The core competencies of the corporation. Harvard Business Review, 68(3), 79-91.

Prahalad, C. K., \& Ramaswamy, V. (2000). Co-Opting Customer Competence. Harvard Business Review, 78(1), 848-881.

Prahalad, C. K., \& Ramaswamy, V. (2004). Co-creating unique value with customers. Strategy \& Leadership, 32(3), 4-9.

Prandelli, E., Verona, G., \& Raccagni, D. (2006). Diffusion of Web-Based Product Innovation. California Management Review, 48(4), 109-135

Ramaswamy, V. (2011). It's about human experiences...and beyond, to co-creation. Industrial Marketing Management, 40(2), 195-196.

Ramaswamy, V., \& Ozcan, K. (2013). Strategy and co-creation thinking. Strategy \& Leadership, 41(6), 5-10.

Ramírez-Montoya, M. S., \& García-Peñalvo, F.-J. (2018). Co-creation and open innovation: Systematic literature review. Comunicar, 26(54), 9-18.

Romero, D., \& Molina, A. (2009). Value co-creation and co-innovation: linking networked organisations and customer communities. Virtual Enterprises, 401-412.

Romero, D., \& Molina, A. (2011). Collaborative networked organisations and customer communities: Value co-creation and co-innovation in the networking era. Production Planning and Control, 22(56), 447-472.

Roser, T., DedFillippi, R., Samson, A. (2013). Managing your co-creation mix: co-creation Ventures in distinctive Contexts. European Business Review, 25(1), $20-41$.

Rudito, Priyanto, P. ., F.N, M., \& M.B.A, S. (2017). Digital Mastery "Membangun Kepemimpinan Digital Untuk Memenangkan Era Disrupsi.” Jakarta: PT Gramedia Pustaka.

Sawhney, O., Verona, G., \& Prandelli, E. (2005). Collaborating to Create: The Internet as Platform for Customer Engagement in Product innovation. Journal of Interactive Marketing, 19(4), 1-14.

Seppanen, M., \& Laukkanen, I. (2016). Business model innovation: Focus on customer experience. 2015 IEEE International Conference on Engineering, Technology and Innovation/ International Technology Management Conference, ICE/ITMC 2015.

Sharma, S., Conduit, J., \& Rao Hill, S. (2014). Organisational capabilities for customer participation in health care service innovation. Australasian Marketing Journal, 22(3), 179-188.

Sheth, J. N., \& Uslay, C. (2007). Implications of the Revised Definition of Marketing: From Exchange to Value Creation. Journal of Public Policy \& Marketing, 26(2), 302-307.

Stamm, B. Von. (2004). Collaboration with other firms and customers : innovation's secret weapon. Strategy \& Leadership, 32(3), 16-20.

Wasono, L. W., \& Furinto, A. (2018). The effect of digital leadership and innovation management for 
incumbent telecommunication company in the digital disruptive era. International Journal of Engineering and Technology, 7(June), 125-130.

Zandi, G., \& Haseeb, M. (2019). The role of trade liberalization in carbon dioxide emission: Evidence from heterogeneous panel estimations. International Journal of Financial Research, 10 (5), 228240.

Zott, C., Amit, R., \& Massa, L. (2011). The business model: Recent developments and future research. Journal of Management, 37(4), 1019-1042.

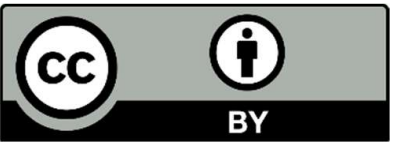

(C) 2019 by the authors; licensee Growing Science, Canada. This is an open access article distributed under the terms and conditions of the Creative Commons Attribution (CC-BY) license (http://creativecommons.org/licenses/by/4.0/). 